\title{
Qualities Required for Civil Engineering Students from a Project Accident
}

\author{
Jingshu Zhang, Yuanlong Yang, Fangmeng Zheng \\ School of Civil Engineering and Mechanics, Lanzhou University, Lanzhou, China \\ Email: jshzhang@lzu.edu.cn
}

Received 2012

\begin{abstract}
Civil engineering educational circles have always been focusing on the professional qualities and cultivation of civil engineering students, which is also problems in civil engineering teaching. In the beginning of professional course teaching, the author introduced an real project accident and specially emphasized that responsibility, teamwork, seriousness, carefulness, comprehensively applying of knowledge, working in accordance with codes are considered as quality requirements of civil engineering students. This teaching thought is carried out through the whole teaching process, which brings deep impression to students and good teaching effect. The teaching thought is introduced in this paper.
\end{abstract}

Keywords: Civil Engineering; Quality; Project Accident

\section{Introduction}

The basic task of engineering education in colleges and universities [1] is to make students accept systematic theoretical knowledge of science and engineering, practice and learn basic skills and be equipped with essential qualities that an engineer should have when they graduate from school. Civil engineering specialty training goal in Lanzhou University[2] is cultivating innovative talents which possesses strong mechanic and engineering theory foundation, have the ability to participate in civil engineering project of scientific research, planning, design, construction and management, suffice to be engaged in research, technology or management work in department of research, design and management in the field of building construction, underground engineering, roads and bridges and be capable of strong ability in engineering practice and preliminary scientific research. Lanzhou university civil engineering specialty offers courses of "masonry structure" in the second semester of the third year and it's also the first professional course. At this time, students' study time in school has passed more than half, and they have mainly completed the foundation courses like mathematics and mechanics, and achieve a status change from students to engineers which they will obtain in practical work. Therefore, the aim of professional teaching is not only to impart knowledge, more important is to cultivate student's quality and enhance work ability. Hence, how to raises the students' quality is a problem that must be paid close attention by civil engineering professional teachers. The author has undertaken teaching work of "masonry structure" course since 2004.In the first class, by an engineering accident as background, the quality civil engineering students should have and the problems caused by a lack of professional quality was introduced. And this will be a reference for engineering teaching fellows.

\section{Engineering Accident Situation}

\section{General situation}

August 13, 2007, the dixi tuojiang bridge which was under construction in fenghuang county, Hunan province, produced special major collapse,64 people killed and 4 seriously injured, causing a direct economic loss of 39.747 million Yuan[3].

The dixi tuojiang bridge started in March 12, 2004, and the planned working period was 16 months. The bridge, which connected fenghuang county in Hunan province and tongren daxing airport in Guizhou province, is one of the important controlling engineering of the fengda Highway projects. The bridge, a kind of multiple-arch stone one, is 328.45 meters length, 13 meters width of bridge deck, 33 meters high of bridge pier, and the bridge type is a 65 meters span with four holes, uniform section, catenaries, hollow and no hinge arch bridge.

When the accident happens, the masonry of abdomen arch ring, side wall and the stuffing on arch has basically completed, the work of dismantling scaffold was near the end. The bridge was planned to be completed in the end of August, and be open to traffic in September 20, 2007, which would be a tribute for xiangxi autonomous prefecture celebration of 50 years.

The bridge constructional enterprise is xiangxi autonomous prefecture fengda highway construction Co., LTD. (referred to as Fengda Company), belongs to the people's government of xiangxi autonomous prefecture, and is a wholly state-owned company. The design and geological exploration unit is Huagang design institute, ownership by the whole people, belongs to Changsha University of Science and Technology, and has class A project design certificate and engineering survey certificate in Highway industry. The construction unit is Hunan Road \&Bridge Construction Group Company (referred to as Road \&Bridge Company), a wholly state-owned large-scale enterprise, has qualification certificates like highway engineering construction general contracting super certificate. A level 2 institution of Road \&Bridge Company, the seventh road company takes charge of the specific construction tasks of the dixi tuojiang bridge. The construction supervising unit is Hunan jinqu traffic consultation and supervision Co., LTD has a class A qualification of highway engineering supervision. 


\section{Accident Cause}

1) The immediate cause of the accident

The construction material of bridge main arch ring can't meet with the requirements of design and standard specification; Construction process of the upper structure of arch bridge is not reasonable; and construction quality of main arch ring is poor, which reduces the integrity and strength of arch ring masonry. With the load on the arch increasing, 3 to 4 meters wide range of the main arch ring, close to abutment zero, and which belongs to No.1 bridge opening, scilicet, the fee of No.2 abdominal arch became invalidated, as masonry strength reached their limit of failure. Affected with multiple arch actions, the whole bridge collapsed quickly.

2) The primary reason of the accident

First of all, the construction unit changed the arch ring construction plan without authorization. The mismanaged construction site and illegal use of construction materials gave rise to the result that the construction of main arch ring do not meet building code requirements, and the main arch ring did not reach the design strength before the scaffold was dismantled.

Second, the project management of the bridge constructional enterprise was in disorder, and it failed to seriously supervise and urge construction unit to put them right when the construction quality problems were discovered. The bridge constructional enterprise lined up with the construction unit altered the construction plan of main arch ring without authorization. Furthermore, the bridge constructional enterprise blindly adopted inverted arrangement for the sake of driving time limit for the project, and was in command of construction beyond its authority, even if asking supervisor not to inspect on the bridge.

Third, the construction supervising units failed to stop the construction unit to alter construction plan of the main arch ring, and cannot effectively supervise and urge construction unit to correct quality problem of main arch ring. When the main arch ring laying completed, it signed acceptance of the project before strength material detected.

Fourth, the design and geological investigation unit illegally subcontract exploration projects to individual, which generated that the design depth of geological survey was not enough, and that the field service and technical interpretation of design intention is poor.

Fifth, the traffic quality control department severely neglected its duty of project quality supervision.

Sixth, two different level of government, xiangxi autonomous prefecture and Fenghuang County, coupled with relevant departments of Hunan province failed to effectively exercise supervision in project approval, bidding, quality and safety production. Autonomous prefecture government asked to drive time limit of the project in order to tribute to xiangxi autonomous prefecture celebration of 50 years.

3) Treatment of the person liable

In the accident, twenty-four people obtained punitive sentences by judicial authority, and thirty-three people received disciplinary sanction of party and political accordingly. As for the construction and supervising unit, the person liable had their professional qualifications and post certificate revoked.

\section{Qualities Required for Civil Engineering Students}

It can be seen form the above accident that people engaged in civil engineering or even the all major in engineering should have such professional quality as follow.

\section{Strong Sense of Responsibility}

Heartbreakingly, such a serious accident could have been prevented thoroughly. As is known to all, Zhao Zhou Bridge, a typical stone arch one, which was built in Sui dynasty, has a history of 1400 years, and can still play traffic function role. As for dixi tuojiang bridge, just a normal stone arch one, it has few technology problems to overcome to build, in the condition that we have far more advanced engineering technology than the ancients. The involved engineering construction units and staffs lacked the sense of responsibility, even committed dereliction, which would take account for the disastrous accident. In the project, the construction unit constructed the bridge with a breach of securities rules, and the site management was in disorder; the bridge constructional enterprise blindly adopted inverted arrangement for the sake of driving time limit for the project, even if asking supervisor not to inspect on the bridge; the supervision unit signed acceptance of the project before inspection; the design and geological investigation unit illegally subcontract exploration projects to individual, which generated that the design depth of geological survey was not enough; quality control department severely neglected its duty of project quality supervision; and the government calls for driving time limit. Therefore, all involved in the project have not performed their duty well. If any side can operate according to the most basic requirement, such serious accidents could have been avoided.

The accident is painful, consequences are severe, and the lesson is profound. The result of the accident is that twenty-four people obtained punitive sentences by judicial authority, thirty-three people received disciplinary sanction of party and political accordingly, and the person liable had their professional qualifications and post certificate revoked. Thus, what the civil engineering students most need to brand on their mind is a revering attitude toward project and a strong sense of responsibility, in spite of what kind of work they will be engaged in after graduate, such as survey and design, construction, engineering supervision, civil servants that work on quality supervision and administration, or further study. The quality requirement is not only for students major in civil engineering, but also for students in all specialties. Only each of us does our duty, can we reduce engineering accidents and build a harmonious society and achieve sustainable development.

\section{Good Team Work Spirit}

The project involves construction unit, constructional enterprise, engineering supervision unit, design and geological investigation unit, the quality supervision departments and related government departments. Each performs its specific tasks, not a single one can be omitted. Entrusted by the construction unit, the geological investigation unit takes responsible for geotechnical engineering, and accomplishes "geotechnical investigation report ". The design unit completes design effort of proposal, preliminary design and construction drawing, delivers the design drawings, and coordinates site work, according to requirements of constructional enterprise, the relevant regulation of the state and "geotechnical investigation report ". The construction unit will complete the construction work in the light of design drawings. The supervision unit which is entrusted by 
the constructional enterprise needs to supervise the quality, progress, safety, and environmental protection of the whole process. As for the relevant government departments conduct the examination, approval and management of project, on the basis of relevant regulation of the state. Therefore, in addition to self-construction house in town, none of project can be finished by any signal unit of above.

In any unit involved in construction, it is also impossible to finish a project by a signal man. Take construction unit for instance, it needs workers and engineer technicians who major in bridges, electrical, engineering economic etc. to cooperate with each other to complete the project. As for workers, it also consists of concrete worker, reinforcing steel bar worker, scaffolder, carpenter, electrician, welder et al. Consequently, unlike traditional scientific research, civil engineering requires people in different specializations cooperate with each other.

For this reason above, team work is one of the most basic requirements to engage in engineering construction. Hence, we should develop a good habit of cooperation and the ability of communication and coordination, which is not only essential for civil engineering staff, but also for researchers and teachers.

\section{Careful and Detailed Work Style}

The difference between specialized course and basic course is that specialty learning doesn't need to do numerous exercises and also skills to solve problems. The requirement of major study is a serious and careful attitude which is capable of considering various indispensable factors, not allowed speculate, and must ensure to do right, rather than wrong.

The reason of such requirement is very simple that the purpose of specialty learning is to engage in the practical project, for which the most basic request is security and economy. In actual work, you may have lapses, but not errors, and never serious mistakes.

The accident was, so to speak, caused by sloppy and unsubtle work. It is a common sense for engineering construction that construction material should be carefully detected and qualified according to building code before applying, but the project failed to do that, at least not seriously. Laying work should be operated according to the construction standard and working procedure, which also failed to implement, so does the supervision unit, design and geological investigation unit, and the quality supervision department. Thus, a series of such mistakes eventually led to the grievous accident.

Ensure to do nothing wrong is the most basic request, but also a very high demand. From elementary school, high school to college, we paid less attention to the result of school assignment. As for examination, even though the result was poles apart, we can still obtain an appropriate score owing to the process of problem solving. Unlike examination, such thing is forbidden in project. For instance, if a single beam or a pillar which was originally insufficient in bearing capacity was proved to be qualified because of miscalculation, it would lead to engineering accident as the result was accepted by construction unit. A little error between original data and design procedure may lead to a large discrepancy, so each data and each a conclusion must be right in actual engineering. In author's specialized course teaching process, the examination was set in practical engineering on that account. When marking, the most important is the result in spite of considering process, which was intended to cultivate student serious and careful work style.

\section{Ability of Comprehensively Applying of Knowledge}

According to the immediate cause of the accident, the project involved many engineering concepts, such as masonry, tectonic, construction process, the arch ring, abdomen arch, arch feet, abutment, load, integrity, strength, failure limit and multiple arch effects. The knowledge that was referred to include specialized course content of "civil engineering construction " and "bridge project", as well specialized basic course point of "civil engineering materials " and "load and design method", and even as far as content involving "civil engineering drawing", "civil engineering surveying", "civil engineering geological", "supervision of project construction", "project management", mathematics and mechanics. Therefore, the essential knowledge of engineering is highly abroad, and students are required to not only master the basic knowledge, but also be capable of comprehensively applying all kinds of knowledge to solving engineering problems [4].

Although every course is important, any course alone can't solve engineering problems. Take architectural structure design work for example, in terms of mathematics and mechanics, the designer should be familiar with the characteristics of all sorts of structure forms, chose economic and suitable one and conduct structure arrangement with wonderful skill, and can also carry on computational analysis of engineering accurately and efficiently so as to map out plans in time. In the design process, the requirement of architecture and equipment and the feasibility of project costs and construction technology should also be taken into consideration. On the side, since the design work is usually accomplished by a large amount of different designer from one or more units, the designers ought to communicate with the constructional enterprise, the construction unit and even supervision unit and project quality supervision unit through design and construction process. Hence, the designers need to deal with communication and coordination work, which requires them to master a certain stock of knowledge in management and humanities and social science. Therefore, civil engineering students must develop the ability of comprehensive application of all kinds of knowledge.

\section{Developing Work Habits in the Light of Standard}

The immediate cause of the accident is that the construction material of bridge main arch ring can't meet with the requirements of design and standard specification. So civil engineering survey, design, construction and supervision must comply with standards and design requirements [5].

When learning basic courses, students know little about standard, but it will be frequently used after being engaged in actual work. All aspects of project construction must be carried out in accordance with relevant construction standard. For instance, geological exploration must follow survey standard; design work must comply with design code. So the process of conducting practical engineering is also, as it were, the process of making use of standard.

To a certain extent, civil engineering study can also be considered as a standard learning process. Mathematics and mechanics, as represented by the basic course, is the foundation of specialized course and specialized basic course, also the elementary knowledge that is necessary to master the standard. The teaching work of such course is directly designed to serve practical engineering, and its content must conform to current 
code. Therefore, when the old standard is canceled and the new one is put into practice, the teaching work should be according to the new standard even if the teaching material has not been updated, otherwise, it is irresponsible for students.

In the process of learning and employing standards, some standard provisions are found not reasonable up to a point and even different and contradictory in different standards, which require us not only to comply with the standard, but also understand its purpose and essence, and flexibly apply the standards to deal with practical engineering problems.

The scientific research of civil engineering in our country is extremely rich, but only a few of which can be applied to engineering and really produce social and economic benefit. And what are widely used are those researches which are mature, reliable, economic and reasonable, and also included in standards. So from this perspective, the purpose of scientific research is to study the standard, and provide technical accumulation for the standard revision which conducts every eight to ten years.

Consequently, whether civil engineering graduates in the future will be engaged in engineering work, such as construction, design, supervision and management or devote them to teaching and scientific research, learning and working in accordance with standards is still one of the most basic requirements.

\section{Conclusions}

Civil engineering education should especially pay attention to cultivating qualities of responsibility, teamwork, seriousness and carefulness, comprehensively applying of knowledge, working in accordance with codes. If we can put them into practice, the serious accident of dixi tuojiang bridge should have been avoided, as well as other accidents. From this project accident, author introduced qualities requirements of civil engineering students, carried it out through the whole teaching process, and achieved good teaching results. Nevertheless, the work that the author has done is limited, there's still much to do about quality education of civil engineering. It is expected that civil engineering colleagues will find out better quality education methods and cultivate excellent engineering talents by further innovating, exploring and meriting from each other.

\section{REFERENCES}

Engineering education research group of Chinese Academy of Engineering. Research on the importance and approach to train Chinese engineers. Research in Higher Education of Engineering, 2005, (1):1-7.

$\mathrm{Wu}$ Jianjun, Zhou Youhe. Civil engineering discipline for producing innovative talents. J. Higher Education of Sciences, 2008, (4):21-23.

Ministry of communications of the people's republic of china. The report on the settlement results about the special major collapse of dixi tuojiang bridge in fenghuang county,Hunan province. Ministry of Communications of the People's Republic of China, 2007.12.

Zhang Jingshu. The basis and practice of building structures design. China Waterpower Press, Intellectual Property Publishing House, 2009.

Zhang Jingshu. The interpretation of common standard provisions in building structures design. China Waterpower Press, Intellectual Property Publishing House, 2009. 